\title{
Epidemiological Considerations on HIV in Constanța County. Aspects of Geographical Distribution on HIV AIDS Cases in Territory. Elements of The HIV AIDS Infections Management with Impact on Environment
}

Şerban IG

\begin{abstract}
The theme chosen is representative of current progress, expressing general public health services in Romania, especially regarding HIV-AIDS healthcare insurance, the specific elements of management epidemiological HIV AIDS impact on the environment.

We have proposed organizing an existing case law database, to elucidate the epidemiological process.

I followed the period 1987-30 June 2013, highlighting some aspects of the geographical distribution of HIV AIDS cases in the county of Constanta.

It has been required the role of epidemiologist - the clinician community!

It has been required the environmental specialist role (biology, engineering) in a hospital for infectious diseases (fundamental role of environmental science).

The role of the multidisciplinary team (biochemist, biologist, epidemiology, infectious disease specialist, hygienist, and psychologist, specialist in environmental ethics and medical ethics, engineer) is relevant. It highlighted the importance of computer science, environmental ethics, Artificial Intelligence, Engineering, Electrical and Electronic Environmental Sciences, Epidemiological Intelligence, Developmental Biology.

The importance of epidemiological monitoring RIS (International Health Regulations) and GIS (Geographic Information Systems) is fundamental.

Is fundamental the Environmental bioethics education (fundamental civilizing factor, located at the intersection of realistic sciences and humanities), in compliance with best practice, guides Bioethics Environmental, procedures, ethical clinical principles and is important to continue the education on environmental thematic, ethical training, according with special literature.

Establishment of databases: valuable epidemiological data on the environmental impact (transmission, non healthy behaviors, iatrogenic).

The need to develop ethical behavior in contemporary modern "transition"society (sexual behavior - MSM, heterosexual, drug users, the MTCT - maternal fetal transmission, environmental hygiene: beaches, road and rail station transportation, social activities, ethological changes).
\end{abstract}

Keywords: HIV-AIDS, Epidemiological Considerations; Geographic Spread; Impact on the Environment.

\section{*Corresponding Author:}

Iulia Gabriela Şerban,

Consultant Epidemiologist, Psychologist, HIV-AIDS Regional Center, Constanta, Romania.

E-Mail: serbaniuliagabriela@gmail.com

Received: January 29, 2015

Accepted: April 01, 2015

Published: April 02, 2015

Citation: Şerban IG (2015) Epidemiological Considerations On HIV In Constanța County. Aspects Of Geographical Distribution On HIV AIDS Cases In Territory. Elements Of The HIV AIDS Infections Management With Impact On Environment. Int J AIDS Res. 02(3), 28-31. doi: http://dx.doi.org/10.19070/2379-1586-150005

Copyright: Şerban IG ${ }^{\mathcal{O}} 2015$. This is an open-access article distributed under the terms of the Creative Commons Attribution License, which permits unrestricted use, distribution and reproduction in any medium, provided the original author and source are credited.

\section{Introduction}

\section{Context of the research in Constanta County}

Constanta is a tourist town with special profile (port, airport), petrochemical industry and Midia Năvodari textile industry - Integrata Cloth factory, agriculture ("IAS" - state farms, "CAP" agricultural production cooperatives), mining industry - Altan Tepae, in the psycho-sociologic-geopolitical context before 1989, the population coming from other counties (Moldova) for work (construction and coastal housing, the Danube - Black Sea Canal, port expansion), risk professions (sailors, airmen, commercial sex workers, prison inmates) and a number of children admitted to pediatric, from unorganized families or abandoned children.

Current - Constanta is an important city of the country, the largest port in South Eastern Europe. Black Sea Coast represents 
over 100,000 locations range accommodation and almost one million tourists in the summer. Currently, the city is developing in many fields, Constanța became the "European City" and international city (Chinese, Thai, Syrian, foreign university students, immigrants from Afghanistan in transition to the Schengen area, tourists from Israel, Nigeria, areas of conflict - epidemiological alerts polio, MERS-CoV, Ebola, injecting drug use, ethnobotanical, airport - spa tourism Techirghiol, Eforie North Grand, social tourism - Vama Veche, cruise ships - international travel, estival carnivals, regular summer-floats, beauty and fashion competitions, bodybuilding culture sports, development of road infrastructure - Sun Highway, the development of the "CFR" Rail stations - Constanta Bucharest distance is traveled by train in the summer just in 2 hours, navigators - shipping companies, international pavilions, work abroad - international oil platforms, the residents of the city, which were established abroad or were teached or worked in Europe, America, Asia, Africa are visiting periodically, or in holidays, the family, hometown, professional travel - shipping, businessmen, academics, athletes), a society in transition "by learning and applying the principles of Western democracy." Current summer employment are selected professional categories (lots of policemen across the country), organized art exhibitions, festivals, opera and ballet, folk and pop music, sports competitions (national, Hagi Football Academy), pilgrimages (Cilic, Dervent, cathedrals), hobby - s (yoga). Tourism is attending swimming pools hotels, spa centers, beauty, manicure, pedicure, and veterinary cabinets (HIV AIDS animals), nature reserves, zoo, Dolphinarium Complex, animal farms.

It requires epidemiological management of the jobs in the past (mining, textile factories, construction) and now the advertising, marketing in supermarkets and hotel industry, institutions deprivation of liberty (prison).

The main objective of this paper is to present some considerations on HIV-AIDS epidemiological period 1987-30 June 2013, highlighting some aspects of the geographical distribution of HIV AIDS cases in the county of Constanta.

\section{Material and Methods}

We conducted a study on two groups of patients selected from the cohort from 1987 to 1989 , based on 2 distinct patterns of evolution: acute (from 1987 to 1993, retrospective study) and chronic course (2008-30 June 2013, study prospective).

We established three groups of patients:

1. Registered in the period 1987-1993, which is mainly cohort of children infected through nosocomial transmission - included in Study I, retrospective.

2. Registered in the period 2008 - 2012 - included in Study II, prospective

3. Registered in the period January-30 June 2013 - included in Study III, prospective, which aims to create a follow-up in terms of other ways to develop rigorous epidemiological investigation, to implement the necessary measures to optimize future prevention. We implemented a model of active surveillance and epidemiological bioethical surveillance, with correlation of all factors, including new and old cases, based on monthly data reporting frequency.
We processed the existing database, the records of consultations; we evaluated health surveys, laboratory data, clinical observation sheets multi -tracking, the register of psychological evaluation.

\section{Results}

A database was analyzed, recorded during 1987-1993. Were first 1728 HIV-AIDS cases, detected in Constanța Region (Table 1).

It appears that in the county, outside the city, higher morbidity values are recorded in Cobadin $(\mathrm{N}=31,1.794 \%)$, Valu lui Traian $(\mathrm{N}=28,1.62 \%)$, Baneasa $(\mathrm{N}=27,1.563 \%)$, Mihail Kogălniceanu $(\mathrm{N}=25,1.447 \%)$, Lumina $(\mathrm{N}=22,1.273 \%)$, Poarta Albă $(\mathrm{N}=$ 20, 1.157\%) (Figure 1-4, Table 2).

It appears many children coming from polling dystrophic $(\mathrm{N}=$ $28,1.62 \%)$.

The vast majority of the population cohort comes from public care and pediatric wards, dystrophic centres, premature infant surgery of Constanta County Hospital.

To these were added detected and diagnosed children in other parts of the country (especially in the west), sent to be supervised in various international partnership programs (Table 3).

21 persons $(F: M=4: 17)$ from other regions of the country, representing $1.215 \%$ of the 1728 patients in the database analyzed (Figure 5, Table 4).

\section{Geographical Distribution On Urban And Rural. Period 1990 - 1992 Hiv Patients, Asymptomatic Hiv And Aids Patients}

In 1990 they were reported a total of 281 asymptomatic HIV patients, of which $60.498 \%$ of urban $(\mathrm{N}=170)$ and $39.502 \%$ of rural $(\mathrm{N}=111)$. Of these, $42972 \%$ from Constanta $(\mathrm{N}=$ 107 - urban hospital). 1-9 years age group ranks first in frequency $(\mathrm{N}=155,55.160 \%)$, followed by age group $20-60$ years $(\mathrm{N}=75$, $26.69 \%$ ).

In 1990 they were reported a total of $655 \mathrm{HIV}$ patients, of which $71.298 \%$ of urban $(\mathrm{N}=467)$ and $28.702 \%$ of rural $(\mathrm{N}=188)$. Of these, $38626 \%$ from Constanta ( $=253$, urban hospital). Age group 1-4 years tops frequency $(\mathrm{N}=404,61.679 \%)$, followed by the age group under 1 year $(\mathrm{N}=146,22.29 \%)$ and $20-60$ years $(\mathrm{N}$ $=85,12,977 \%)$.

In 1990 they were reported a total of 406 AIDS patients, of which $73.153 \%$ of urban $(\mathrm{N}=297)$ and $26.847 \%$ of rural $(\mathrm{N}=109)$. Of these, $35961 \%$ from Constanta ( $\mathrm{N}=146$ - urban hospital).

Age group 1-4 years tops frequency $(\mathrm{N}=284,69.951 \%)$, followed by the age group under 1 year $(\mathrm{N}=112,27.586 \%)$ and 20-60 years $(\mathrm{N}=10,2.463 \%)$.

Comparing reports made in 1990,1991 and 1992 are obtained the figures (Figure 6-8):

It is found that 244 children from orphanages, representing $14.12 \%$ in total. If we consider the children lost in the record (38), there is obtained a percentage of $16.319 \%$ of the total general: 


\begin{tabular}{|c|c|c|c|c|c|c|c|}
\hline \multicolumn{9}{|c|}{ Children from orphanages, swings, foster care: } \\
\hline F & $\%$ from total & M & $\begin{array}{c}\text { \% from } \\
\text { total }\end{array}$ & $\begin{array}{c}\text { Lost out } \\
\text { from record }\end{array}$ & $\begin{array}{c}\text { \% from } \\
\text { total }\end{array}$ & Total & $\%$ from total of the patients (1728) \\
\hline 117 & $41,489 \%$ & 127 & $45,035 \%$ & 38 & $13,475 \%$ & $282-100 \%$ & $16,319 \%$ \\
\hline
\end{tabular}

\section{Phase Conclusion}

1. During 1987 to 1990 there was an uninformed population on HIV-AIDS phenomenon, which later will become familiar with the existence of infection, transmission patterns and healthcare opportunities (after 1990).

2. The route of transmission was: transfusion, injections (parenteral, $84.549 \%$ ). The treatments were performed in pediatric wards (Pediatrics I - N $=78,4.514 \%$ and Pediatrics II - N $=337,19.502$, accumulating a total of $\mathrm{N}=415,24.016 \%$ ), and the parenteral treatments in other sections (dystrophic, premature baby, swings).

3. Orphan patients came from wards dystrophic and premature, mostly being institutionalized or abandoned children.

4. The epidemic was characterized as follows: rural type $(\mathrm{N}=$ $635,36.748 \%$ ), which , together with the percentage of the institutionalized children ( $14.12 \%$ ), forming about $51 \%$ ( $50.868 \%$ ), the rest being found in urban ( $49.132 \%)$. After 1989 , rural- urban social mobility is an explanation of urbanization trend, which persists in 1990, 1991 and 1992, with a better detection of infection in city.

5. There was an epidemic, due to the number of cases diagnosed within a very short time.

6. The evolution of the epidemic had imposed unprecedented organizational measures of health services, to ensure optimal support of a large number of cases (creation of additional space for pediatric population near Constanta Municipal Hospital, where they were brought all HIV-positive children from orphanage, to ensure their uniform assistance).

\section{Period $2008-2012$}

For examinations performed in the emergency room, access was easy Constanta $(\mathrm{N}=658,36.698 \%$ of the total $\mathrm{N}=1793$ consultations performed) Medgidia ( $=143, \mathrm{~N}=17937975 \%$ of consultations), Năvodari ( $\mathrm{N}=123,6.86 \%$ of $\mathrm{N}=1793$ examinations).

In 2010, there were carried out most of the examinations, compared to previous years. A better control of the disease has led to fewer appeals for consultations and hospitalizations (Figure 9-12).

There have been a total of 134 consultations for vertical exposure, including: Constanta $(\mathrm{N}=41,30.597 \%)$, Hârşova $(\mathrm{N}=9$, $6.716 \%$ ), Medgidia ( $=8,5.97 \%$ ). Vertical exposure assessment was performed at 2 months $(\mathrm{N}=13,9.701 \%), 1$ year $(\mathrm{N}=38$, $28.358 \%)$ and 2 years $(\mathrm{N}=20,14.925 \%)$.

\section{Phase Conclusion}

1. Patients are cared for primarily in family -friendly environment in all aspects: environment, help, human and material support, and therapeutic discipline.

2. Epidemic is an urban epidemic, with new cases detected with heterosexual transmission route and newly diagnosed pa- tients with late presentation (late - presenters).

3. It is an established epidemic, based in particular on new methods of transmission, IDU, unprotected sex, changing psychological profile of young adults (exposure to risk factors - tattoos, piercing, ethno botanical, drugs, and casual sex).

\section{Period January - 30 June 2013}

Distribution of patients in the study group by locality of origin (home) is: Constanta ( $\mathrm{N}=80,33.613 \%)$, Năvodari $(\mathrm{N}=13$, $5.462 \%$ ), Medgidia ( $=11,4.622 \%$ ), Ovidiu $(\mathrm{N}=10,4.202 \%)$, Lazu ( $N=9,3.782 \%)$, Mihail Kogălniceanu ( $=8,3.361 \%$ ), Cernavoda, Lumina, Ciobanu and Mangalia ( $=6,2.521 \%$, Basarabi, Cuza Voda and Poarta Albă (N = 5, 2.101\%). Easiest access is from Constanta and Năvodari, followed by Medgidia and Ovidiu (Figure 13-16).

It outlines a new epidemiological entity for surveillance, the occurrence of infectious accidents in HIV-AIDS Department (Table 5, 6):

\section{Phase Conclusion}

1. The epidemic is urban type. More women hospitalized $(\mathrm{N}=$ 136, $57143 \%)$, compared to men ( $=102,42.857 \%)$.

2. It is an evolving epidemic, whose control requires time, is long lasting. Now is difficult to apply the "Directive 0" (Hilary Clinton).

3. Evolution of HIV infection has led to a highly complex pathologies (practically new medicines), which imposed the need to address the multidisciplinary team (environmental specialist role).

\section{Discussion}

We focused on the presence of the F subtype in Romania in general, "an island in a sea of B subtype", and specially in Constanta, that shows a possible infection through " single source "which contradicts the route of transmission by transfusion, which was presented by the existing epidemiological surveys, approved at this time. The epidemiogen potential of F1 strain is important, given the large number of cases and the epidemic character. The import infection remains undervalued, as demonstrated phylogenetic relationship between strains HIV1 subtype F1, isolated in Angola and Romania, presented by Paraschiv S, Steel D. - "HIV - 1subtypes and resistance in Romania" on 2 - 4 September 2010 at the International School" HIV Medicine 2010' edition - II, Constanta, Hotel Ibis, organized by Baylor College of Medicine, Texas Children's Hospital, University Ovidius University Carol Davila Bucharest, citing the study" Close phylogenetic relationship between Angolan and Romanian HIV-1 subtype F1 isolates", authors: Monick L Guimaraes, Ana Carolina P Vicente, Koko Otsuki, Rosa Ferreira, FC da Silva, Moises Francisco, Filomena Gomes da Silva, Ducelina Serrano, Mariza G Morgado, Gonzalo Bello. 
Was implemented the monitoring system of patient satisfaction. During 2011-30 June 2013 were analyzed in total 450 questionnaires of satisfaction of patients from HIV-AIDS Department, representing $21.93 \%$ of the questionnaires. HIV-AIDS patients are satisfied with the medical, psychological and general conditions of hospitalization - hotel, eating, hospital environment. Epidemiological and psychological educational strategy can be effective in creating responsible attitudes among medical personnel employed, patients and society in general. The role of multidisciplinary teams (biochemist, biologist, epidemiology, infectious disease specialist, hygienist, and psychologist, specialist in environmental ethics and medical ethics, engineer) is fundamental to achieving consistent results over time. Implementation of a quality system is a long process and requires awareness, involvement of all available resources, continuous improvement.

Environmental impact is complex. Environmental aspects cover the following:

1. Geographical distribution of HIV-AIDS cases in the county of Constanta, in the city (originally, from 1987 to 1990: industry, petrochemicals, construction, shipyard, airport, ports on the Danube and the Black Sea) and rural (agriculture, industry, agricultural mechanics, viticulture areas, mining, livestock).

- Sources of swings, orphanages, dystrophic centers, placement, neuro psychiatrics.

- Sources from other geographical regions of the country. Distribution of HIV children stratified by place of origin of their parents, according to work abroad of parents and carers, depending on the place of origin of their parents. Routes of social mobility (occupational population migration - émigration, immigration) (Figure 17).

- Period 2008 - 2013: easy access for consultation to the emergency room of the nearby localities of the city (the criterion of accessibility of the territory)

- Geographical distribution of cases of vertical HIV-AIDS exposure (MTCT - maternal fetal transmission), of the deaths.

2. Safety-hospital environment (water quality, wastewater treatment, chlorination, hotel conditions, supply of antiseptic, disinfectant for surfaces and stocks clorigene, compliance epidemiological circuits, operation of elevators, the safety of the transfused blood - testing blood, transfusion unit epidemiological integrated circuits, similar Intensive Terapy and operating theaters, plan for legionella - hydro network diagram, administrative measures, air disinfection - epidemic measures for MDR-TB, XDR-TB, poli hospitaliyations, neonatology. Role of good medical maneuvers (iatrogenics). Respecting universal precautions. Monitoring of the infectious accidents occurring in HIV AIDS Department, at the medical staff. Important role on epidemiological training of medical staff.

It has been required the role of epidemiologist - the clinician community!

a. Elements of epidemiological HIV AIDS management with impact on the environment

b. Epidemiologic and environmental management of Blood Transfusion Unit

c. Epidemiological and environmental management of the epidemiological circuits in hospital, drinking water, treatment water station.

d. Epidemiological and environmental management on control of nosocomial infections (hospital laboratory control).

e. Epidemiological and Environmental Management's orphanages, dystrophic centers, pediatric palliative care.

It has been required the environmental specialist role (biology, engineering) in a hospital for infectious diseases (fundamental role of environmental science).

Collaboration in hospital between epidemiologist and environmental specialist is essential.

3. Distribution of the risky landmarks in territory (HIV-AIDS in animals, nature reserve, zoo, children's recreational purposes) 4. Territorial distribution of potential "sources of risk" (prisons, summer clubs, HIV laboratories, neuropsychological patients, drugs, sex tourism - sex workers, professionals risk - long-haul drivers, pilots, sailors, isolated population - religious sects, unemployed laborers, delegates, MSM - men having sex with men, marital status - divorce, remarried, blood donors).

5. Role of the general medical education (condom, first aid, family planning) - schools, healthcare, mass media, NGO - s, church...

Is fundamental the Environmental bioethics education (fundamental civilizing factor, located at the intersection of realistic sciences and humanities), in compliance with best practice, guides Bioethics Environmental, procedures, ethical clinical principles and is important to continue the education on environmental thematic, ethical training, according with special literature.

Establishment of databases: valuable epidemiological data on the environmental impact (transmission, non healthy behaviors, iatrogenic).

The need to develop ethical behavior in contemporary modern "transition" society (sexual behavior - MSM, heterosexual, drug users, the MTCT - maternal fetal transmission, environmental hygiene: beaches, road and rail station transportation, social activities, ethological changes).

\section{References}

[1]. Goodman N (1992) Introducere în sociologie. Editura Lider, Bucureşti.

[2]. Vollmann J (2013) The Implementation Process of Clinical Ethics Consultation: Concepts, Resistance, Recommendations. Revista Română de Bioetică. 11(3): 108. www.bioetica.ro

[3]. Mătuşa R, Ilie M (1992) Clinical Description of 650 children with AIDS in Constanţa, România. Management of pediatric HIV (Oral Abstract), VII International Conference on AIDS, III STD World Congress, Amsterdam, The Netherlands. 1: $19-24$. Abstract TuB0515

[4]. Mătuşa R, Ilie M, Cernescu C (1994) Neurological manifestations of HIV infection AIDS in children. Tenth International Conference on AIDS, International Conference on STD, Yokohama, Japan.1:7-12. Abstract PB0467.

[5]. Cuzic V (2009) HIV infection in children: epidemiological and clinical aspects in Constanta County.TEZĂ DE DOCTORAT.

[6]. http://www.umfcv.ro/files/h/i/HIV\%20infection\%20in\%20children $\% 20$ epidemiological\%20and\%20clinical\%20aspects $\% 20 \mathrm{in} \% 20$ Constanta $\% 20$ County.pdf.

[7]. Mărdărescu M (2010) Pediatric HIV Infection and mother to child transmission in Romania between ideal - Possibility Reality”, Şcoala Internaţională - "Medicina HIV în 2010", Ediţia a - II - a, Constanţa, Hotel Ibis.

[8]. Rugină S (2010) The HIV Center of Excellence Constanţa, Romania - A Model of HIV Clinical Assistance, "Medicina HIV în 2010”, Ediţia a-II-a, Constanţa, Hotel Ibis. 